\title{
REFORMA DA EDUCAÇÃO SUPERIOR NO BRASIL: ANÁLISES SOBRE A TRANSNACIONALIZAÇÃO E PRIVATIZAÇÃO
}

\section{The Reformation of the Superior Education in Brazil: Analyses on the Transnationalization and Privatization}

\section{Resumo}

Deise Mancebo ${ }^{1}$

O texto propõe-se analisara reforma da educação superiorem curso no Brasil. Parte da discussão da legislação já aprovada que, direta ou indiretamente, diz respeito a esse nível de ensino e analisa o terceiro Anteprojeto de Lei da Reforma da Educação Superior a partir de dois eixos: o da soberania nacional para a prestação desse serviço e o da privatização do sistema de educação superior.

Palavras-chave: Reforma da educação superior; Transnacionalização; Privatização.

\section{Abstract}

The text proposes the analysis of the reform of the higher education in course in Brazil. It begins discussing the legislation already approved that, directly or indirectly, concerns to this level of education and it analyzes the third "Project of Higher Education Reform" from two points of view: the national sovereignty for the development of that service and the privatization of the higher education system.

Keywords: Higher education reform; Transnationalization; Privatization.

1 Doutora em História da Educação pela Pontifícia Universidade Católica de São Paulo (PUC/SP), com pós-doutorado pela Universidade de São Paulo (USP). Professora e pesquisadora do Programa em Políticas Públicas e Formação Humana da Universidade do Estado do Rio de Janeiro (PPFH/UERJ) e do Programa de Psicologia Social da mesma universidade. Email: mancebo@uerj.br. 
[...] cair na tentação dos reparos institucionais formais - "passo a passo", como afirma a sabedoria reformista desde tempos imemoriais - significa permanecer aprisionado dentro do círculo vicioso institucionalmente articulado e protegido dessa lógica autocentrada do capital (MÉSZÁROS).

\section{Os Preâmbulos da Reforma da Educação Superior no Brasil: 2003/2005}

Há aproximadamente três anos, praticamente desde o início do governo de Luís Inácio Lula da Silva, debate-se no país uma reforma da educação superior. Até a presente data ${ }^{2}$, três anteprojetos já foram propostos pelo Ministério da Educação e Cultura (MEC): a primeira versão foi apresentada em dezembro de 2004, depois de um processo de discussão que envolveu diversas entidades e gerou muita polêmica; para a segunda versão, de maio de 2005, o Ministério recebeu 121 emendas e ajustou o Anteprojeto de 100 para 72 artigos; por fim, em 29 de julho de 2005, foi divulgado o terceiro Anteprojeto de Lei da Reforma da Educação Superior, com 69 artigos, sem novidades significativas em relação aos dois anteprojetos anteriores e que será fruto de análise no presente texto.

A iniciativa governamental de promover uma reforma da educação superior representa um empreendimento positivo, praticamente impensável em governos anteriores, e o fato do Anteprojeto abranger regulações que afetam o conjunto das instituições de educação superior no país, um total nada desprezível de 1859 instituições tanto públicas quanto privadas, 0 alça à condição de um dos documentos mais importante das últimas décadas nesta área (BRASIL, INEP, 2003).

Todavia, o terceiro Anteprojeto de Lei da Reforma da Educação Superior foi antecedido por ampla legislação que, direta ou indiretamente, já delineia os "novos" rumos da educação superior no país e que, em grande medida, define estreitos limites para eventuais avanços em direção contrária ao movimento de privatização que grassa no sistema de educação superior brasileiro. Além da regulamentação das Fundações de Direito Privado; dos diversos projetos de lei e decretos que tratam da reformulação da educação profissional e tecnológica ${ }^{3}$; é preciso destacar para breve apresentação e análise quatro medidas legais, todas já aprovadas, que se constituem em importantes precedentes para a futura reforma desse nível de ensino (DECRETO n. $\stackrel{0}{ }$ 5.205 de 2004).

2 Como se trata da análise de um processo em curso, a leitura desse trabalho deve considerar, obrigatoriamente, o momento em que foi escrito: novembro de 2005

3 Decreto n. - 5.154, de 23 de julho de 2004 (que reorganiza a educação profissional); Decreto n. ${ }^{-5224 / 04}$ (que dispõe sobre a organização dos Centros Federais de Educação Tecnológica). 
Reforma da educação superior no Brasil: análises sobre a transnacionalização e privatização

Sistema Nacional de Avaliação da Educação Superior

Cronologicamente, a primeira medida legal proposta e aprovada, que se refere à educação superior, no atual governo, foi a Lei n.. 10.861 , de 14 de abril de 2004, que institui o Sistema Nacional de Avaliação da Educação Superior (SINAES).

A discussão, aprovação e implementação da nova avaliação da educação superior foram, por certo, uma das pautas mais polêmicas desses três anos de governo, no campo da educação superior. A avaliação constituiu-se no carro-chefe das políticas educacionais no governo de Fernando Henrique Cardoso, e qualquer tentativa de mudança nas regras de avaliação, como de fato se fez no governo atual, implicava o aparecimento de críticas veiculadas, generosamente, pela grande imprensa, especialmente quando se tratava de modificações ou da extinção, como acabou ocorrendo, do Exame Nacional de Cursos.

O já extinto Exame Nacional de Cursos, mais conhecido como "Provão", era um instrumento quase exclusivo de avaliação, aplicado ao final dos cursos de graduação, editado inicialmente pela Medida Provisória n.ํㅜ 1.159 de 26/10/1995, transformada, posteriormente, na Lei n. - 9.131, de 24 de novembro de 1995. O resultado do "Provão" era amplamente divulgado pela grande imprensa e sua valorização era coerente com a concepção de que "compete ao Estado apenas avaliar as instituições e estimular a concorrência entre elas, no caso pela divulgação de rankings, o que permitiria ao 'mercado consumidor' de educação escolher as 'melhores' instituições" (ROTHEN; SCHULZ, 2005, p. 6-7).

Diferentemente, com o SINAES, instituiu-se um sistema muito mais complexo de procedimentos avaliativos, envolvendo três dimensões básicas: a avaliação das instituições de ensino superior, dos cursos de graduação e do desempenho acadêmico dos estudantes, por meio do ENADE (Exame Nacional de Desempenho dos Estudantes), que utiliza duas provas para a avaliação dos estudantes, uma aplicada na entrada e outra na saída, realizadas por amostragem, em substituição ao Provão. Os idealizadores mais diretos das novas ações de avaliação, responsáveis pela publicação da proposta original, pretendiam remeter à construção de uma nova cultura avaliativa de natureza formativa, que fosse capaz de firmar ao mesmo tempo, em todas as instituições, públicas ou privadas, a consciência de sua função pública e de seu compromisso público inarredável com a sociedade brasileira. (MANCEBO, 2004b).

Todavia, apesar dos grandes avanços reconhecidos em relação ao "Provão", este novo Sistema vem sendo alvo de críticas. Primeiramente, questionam-se as mudanças que ocorreram ao longo do processo de discussão dessa lei que acabaram por fortalecer os resultados da avaliação como um 
referencial básico dos processos de regulação e supervisão da educação superior, ao invés do caráter formativo inicialmente advogado na proposta original (ROTHEN; SCHULZ, 2005). Esse reforço no controle do sistema, em detrimento do caráter formativo, também tem levado os críticos a acusarem o SINAES de não respeitar a autonomia universitária. Por fim, questiona-se o caráter excessivamente centralizador da nova avaliação, principalmente, na constituição da Comissão Nacional de Avaliação do Ensino Superior (CONAES), responsável pelas principais diretrizes e normas relativas ao Sistema.

\section{Lei de Inovação Tecnológica}

A segunda legislação que merece destaque é a Lei n.. 10.973 , conhecida como Lei de Inovação Tecnológica, de 2 de dezembro de 2004, que dispõe sobre incentivos à inovação e à pesquisa científica e tecnológica no ambiente produtivo. Esta lei - que poderá afetar a universidade em profundidade, pois cria procedimentos mais rápidos de transferência e licenciamento de tecnologia das entidades de pesquisa para a indústria - foi discutida, basicamente, por iniciativa do Ministério da Ciência e Tecnologia e, portanto, encaminhada literalmente "a parte" dos debates sobre a Reforma Universitária.

Sinteticamente, pode-se afirmar que a Lei de Inovação Tecnológica organiza-se em torno de três eixos: a constituição de ambiente propício a parcerias estratégicas entre as universidades, institutos tecnológicos e empresas; o estímulo à participação de instituições produtoras de conhecimento, no processo de inovação; e o incentivo à inovação nas empresas. Esses princípios concretizam-se, ao longo do texto legal, em diversos procedimentos, doravante possíveis e/ou facilitados, como: a transferência de tecnologia das universidades e centros de pesquisa para as empresas; a incubação de empresas no espaço público; o compartilhamento de infra-estrutura, equipamentos e recursos humanos, envolvendo instituições de pesquisa e empresas, mesmo em espaços públicos; 0 afastamento de pesquisadores das universidades públicas para tentar transformar seus inventos em negócios; o pagamento de incentivos adicionais a pesquisadores-docentes dedicados a projetos de inovação em parceria com empresas, com recursos captados pela própria atividade; a alocação de recursos públicos para empresas nos projetos considerados como de inovação; o aporte de recursos orçamentários diretamente à empresa, no âmbito de um projeto de inovação; bem como a participação dos órgãos públicos de pesquisa nos lucros gerados pela transferência de tecnologia.

Para o Ministério da Ciência e Tecnologia, uma das conseqüências esperadas a partir da aplicação dessa lei, na realidade uma adaptação de legislação vigente em países centrais, reside na "implementação de um novo e 
mais flexível marco regulatório na relação entre a economia e os institutos públicos de pesquisa, que aumentará as chances de participação de empresas brasileiras no mercado internacional com condições de competir com a tecnologia de outros países" (MANCEBO, 2004a, p. 856). Desse modo, para atender às prioridades das políticas industrial e tecnológica, a União vai incentivar as empresas a apoiar e investir em atividades de pesquisa e desenvolvimento tecnológico por meio da concessão de recursos financeiros, humanos, materiais e de infra-estrutura, com profundas repercussões para as universidades brasileiras, conforme já discutido em texto anterior (MANCEBO, 2004a):

A par da hierarquização que tal projeto poderá impor à universidade, aprofundando um processo em que unidades, grupos e mesmo instituições terão condições de trabalho, regimes de funcionamento e salários diferenciados, os principais riscos dessa Lei ficam por conta da mercantilização do conhecimento, do arrefecimento do potencial crítico que a universidade dispõe desde sua gênese (p. 856).

Por fim, há que se destacar os riscos que essa Lei traz para a autonomia universitária, podendo-se antever um aprofundamento da submissão e dependência da agenda acadêmica aos recursos, à direção e ao controle não somente do Estado mas, em especial, ao mercado (SGUISSARDI, 2002, p.123).

\section{A Lei da Parceria Público-Privada}

A terceira legislação a ser comentada é a Lei n. ${ }^{0} 11.079$, de 30 de dezembro de 2004, que institui normas gerais para licitação e contratação de Parceria Público-Privada (PPP) no âmbito da administração pública.

A justificativa central para a edição desta Lei foi que, diante da falta de recursos para investimentos, da pesada dívida pública herdada de governos anteriores, da necessidade de retomar o crescimento econômico e de gerar empregos, o governo necessita de investimentos privados e, portanto, das parcerias público-privadas. Todavia, o texto da Lei é demasiado abrangente, delegando atribuições do Estado à iniciativa privada para todos os tipos de empreendimentos e gestão, inclusive para os serviços públicos sociais, incluindo, portanto, saúde e educação, por exemplo. "Regular, legislar e policiar" são os únicos domínios de responsabilidade governamental que ficarão interditados às PPPs. Todos os demais campos de atividade estatal, quer se trate da produção e comercialização de bens e serviços de natureza pública e coletiva, da pesquisa e do desenvolvimento tecnológico, da defesa do meio ambiente, da conservação do patrimônio histórico e cultural, da representação externa dos interesses da Nação e do Estado, bem como do oferecimento de formação 
superior, enfim, todos esses campos ficarão abertos à contratação de parcerias (JURUÁ, 2004).

Portanto, a racionalidade que preside essa Lei reside na desobrigação do Estado em relação à prestação de serviços, com a conseqüente mercantilização destes, devendo-se relevar, ainda, a consideração governamental da suposta superioridade gerencial privada para a condução de qualquer "negócio". As teses defendidas há muito tempo pelo Banco Mundial e pelo Fundo Monetário Internacional (FMI), que versam sobre o abandono imediato dos objetivos de universalização dos serviços públicos e a focalização da ação governamental em programas assistenciais, destinados à população mais pobre e miserável, ganham consistência legal com essa legislação que, pela sua extensão, viabiliza a redução do papel do Estado na assistência pública, dá excesso de garantias ao setor privado, incluindo a utilização de recursos públicos por entidades privadas, opondo-se aos interesses públicos e ao princípio constitucional de universalização de alguns serviços como a educação.

Por fim, não se pode deixar de registrar que a aprovação das PPPs também "correu" por fora das discussões sobre a Reforma Universitária e que apesar dos profundos impactos que poderá causar - e já está causando, como se verá no próximo item - ao sistema de educação superior, mesmo o MEC teve um papel marginal na discussão dessa Lei.

\section{Programa Universidade para Todos}

A quarta e última medida já aprovada, que traz repercussões diretas para a privatização da educação superior, é a Lei n. ํㅜ 11.096, de 13 de janeiro de 2005, que institui o Programa Universidade para Todos - ProUni.

Tal Programa prevê o aproveitamento, sob a forma de bolsas integrais ou não, de parte das vagas ociosas das instituições de ensino superior privadas, de modo a possibilitar a elevação da taxa de matrícula e viabilizar 0 ingresso de novos alunos em curto prazo de tempo. Na realidade, institucionaliza a troca de cerca de $10 \%$ das vagas das instituições privadas ou de $8,5 \%$ da sua receita bruta, na forma de bolsas para alunos egressos de escolas públicas, entre outros critérios, em troca de isenção para as instituições participantes de um conjunto de impostos.

A justificativa oficial para a proposição do Programa residiu (1) na necessidade de expandir as vagas para a educação superior (pois, atualmente, somente $11 \%$ da população na faixa etária de 18 a 24 anos freqüenta algum tipo de curso de educação superior), em especial, para a população mais pobre, inclusive com parte das bolsas direcionadas a ações afirmativas (aos portadores de deficiência, aos autodeclarados negros e indígenas, bem como 
para a formação de professores de ensino básico da rede pública), (2) na constatação da existência de um crescente número de vagas ociosas nas instituições de ensino superior privadas. Todavia, outras "justificativas" vêm sendo apontadas pelos críticos, como é o caso de Carvalho (2005), quando afirma que "o Programa Universidade para Todos (ProUni) surge acompanhado por um discurso de justiça social, cujo principal indicador é a baixa escolaridade líquida", mas que, na realidade, "trata-se [...] de criar condições para a sustentação financeira dos estabelecimentos [privados]já existentes", diante dos limites estruturais no poder aquisitivo de sua clientela. A autora complementa:

A queda nos rendimentos reais e o nível elevado de desemprego dificultam a sustentação dos gastos com as mensalidades pelos assalariados. O Programa Universidade para Todos surge, assim, como excelente oportunidade de fuga para frente para as instituições ameaçadas pelo peso das vagas excessivas (CARVALHO, 2005, p. 10).

Tal análise é constatada pelo próprio setor. Um estudo desenvolvido por três consultorias da área educacional - Hoper Educacional, CM Consultoria e Ideal Invest - intitulado "Análise Setorial do Ensino Superior Privado no Brasil - Tendências e Perspectivas 2005-2010", divulgado no "VII Fórum Nacional: Ensino Superior Particular Brasileiro", ocorrido em São Paulo, em outubro de 2005, prevê uma crise no setor, advertindo que as instituições mais novas e com menos alunos irão enfrentar uma sucessão de fusões, incorporações e falências, visto que as instituições privadas de ensino superior, em 2005, apresentaram um quadro de $42 \%$ de vagas ociosas. A esse diagnóstico, 0 senhor Hermes Ferreira Figueiredo, presidente das entidades mantenedoras de estabelecimentos de ensino superior de São Paulo (SEMESP), complementa: "temos de buscar formas alternativas de financiamento, seja privado ou público, como o FIES e o PROUNI" (CAFARDO, 2005).

Pouco importa se a "fuga para frente" era ou não a intenção governamental original. Concretamente, o pólo privado saiu fortalecido com a institucionalização do Programa, tanto mais após a tramitação legal no Congresso (de Medida Provisónia a Lei do ProUni), onde as alterações impressas no texto legal conduziram à maior flexibilização de requisitos e sanções e à redução da contrapartida das instituições particulares a serem beneficiadas com a renúncia fiscal.

Existe amplo consenso sobre a necessidade de expansão do acesso à educação superior e, sob esse aspecto, é louvável a atenção que o governo dispensou ao tema. Não obstante, o "Programa Universidade para Todos" é digno de muitas críticas. Primeiramente, a renúncia fiscal em nome da expansão do acesso realiza-se, salvo raras exceções, com o sacrifício da qualidade, pois essa é uma característica insofismável da maior parte das instituições 
privadas neste nível de ensino. Mas os problemas não param aí e a principal crítica que se pode fazer reside nas relações que o Programa estabelece com o setor privado de ensino superior: contribui para o aumento da oferta privada nesse campo; possibilita o financiamento público indireto para os estabelecimentos de ensino superior privados, pois é bem esse o caso da renúncia fiscal; e fortalece o setor privado que mais se expandiu nos últimos anos, isto é, o com fins lucrativos. Como resultado de toda essa operação, responsabilidades públicas são repassadas a entidades privadas, ocorre "um embaralhamento das barreiras entre o público e o privado", podendo ser considerado o primeiro caso de aplicação das parcerias público-privadas, anteriormente discutidas, no âmbito da educação superior (MANCEBO, 2004b, p. 86).

Tal quadro tem condicionantes históricos e estruturais na nossa história recente que implicaram mudanças nas quais o econômico tem dado o tom. Sob o pretexto de racionalização de recursos, estimula-se uma série de ações delegatórias, promovendo iniciativas empresariais destinadas a substituir ou a complementar as responsabilidades que os governos recusam, ou assumem apenas parcialmente. Assim, além de uma decisão de ordem econômica, "[...] trata-se de uma decisão política sustentada na necessidade de gerar uma profunda redefinição do papel do Estado brasileiro" (MANCEBO, 2004b, p. 87).

\section{Lei da Reforma da Educação Superior: Análise Crítica do Anteprojeto}

É deste patamar que se parte para a análise do terceiro Anteprojeto de Lei da Reforma da Educação Superior. Na realidade, a legislação acima apresentada configura um mapa administrativo-legal que parece dar continuidade às políticas da ortodoxia neoliberal no campo da educação superior, bem como no da ciência e da produção tecnológica. Assim, já se parte para a análise do Anteprojeto de forma crítica, antevendo diversos problemas. Dentre inúmeras possibilidades, este texto destaca dois aspectos principais para análise: no primeiro, discute a questão da soberania nacional para a prestação da educação superior e, no segundo, comenta criticamente as múltiplas facetas da privatização do sistema nacional de educação superior, passíveis de ocorrência a partir da aprovação do Anteprojeto.

\section{Educação Superior e Soberania Nacional}

A transnacionalização das trocas universitárias é um processo antigo, aliás, quase matricial, porque visível desde o início nas universidades européias medievais (SANTOS, 2004, p. 18). Todavia, a intensificação dos intercâmbi- 
os universitários que agora se assiste não é um incremento da internacionalização do saber ou dos intercâmbios culturais e científicos entre universidades e pesquisadores de diversos países do mundo. Trata-se de uma nova transnacionalização, alimentada pela crise do capital deste setor e por sua busca de novos campos de exploração; pela ação dos organismos internacionais que tentam criar as condições necessárias para que este movimento por novos mercados aconteça e pela subserviência de governos à lógica do capital. Portanto, trata-se de uma transnacionalização muito mais vasta que a anterior e, o que é mais importante, baseada em uma lógica primeiramente mercantil. A preocupação com esse "segundo" movimento transnacional é que conduzirá a análise apresentada a seguir.

No terceiro Anteprojeto de Lei da Reforma da Educação Superior, está previsto o estabelecimento de parcerias com as instituições estrangeiras. Ele autoriza uma participação de até 30\% de capital estrangeiro (Art.13, §4) do capital total e do capital votante das entidades mantenedoras das instituições de ensino superior, quando constituídas sob a forma de sociedade com finalidade lucrativa. Estabelece, assim, o princípio segundo o qual a educação superior no Brasil pode contar com investimentos estrangeiros e já cria parte da "segurança jurídica", que os empreendedores tanto reivindicam nos Tratados de Livre Comércio.

Às empresas e universidades estrangeiras fica garantida, pois, uma boa movimentação no promissor "mercado educacional brasileiro", o que poderá ocorrer, por exemplo, por meio da educação superior à distância (EAD), conforme previsto no artigo 11 do Anteprojeto.

Por fim, o Anteprojeto prevê a possibilidade de reconhecimento, por instituições privadas brasileiras, de diplomas de mestrado e doutorado expedidos por instituições estrangeiras, prerrogativa que até então era exclusiva das instituições públicas (artigo 7), consolidando a possibilidade de associações das empresas situadas no país com as corporações multinacionais para os cursos de pós-graduação.

As prerrogativas anteriormente expostas abrem um amplo caminho para articulações de instituições privadas nacionais com o capital internacional, relacionado ou não ao setor, possibilita negociações transnacionais de vulto e cobiçadas há muito tempo pelos organismos internacionais. Conforme Santos (2004):

[...] as despesas mundiais com a educação ascendem a 2000 bilhões de dólares, mais do dobro do mercado mundial do automóvel. É, pois, à partida, uma área aliciante e de grande potencial para um capital ávido de novas áreas de valorização [...e] os analistas financeiros têm chamado a atenção para 0 potencial de a educação se transformar num dos mais vibrantes mercados no século XXI (p. 27). 
Desde 2000, essa transnacionalização da universidade ocorre sob a égide da Organização Mundial do Comércio no âmbito do Acordo Geral sobre o Comércio de Serviços (GATS). A educação é um dos doze serviços abrangidos por este acordo e o objetivo deste é promover a liberalização do comércio de serviços através da eliminação, progressiva e sistemática, das barreiras comerciais (p.32).

Nas Américas, desde 1994/1995, um conjunto de acordos vem dando contorno à ALCA (Área de Livre Comércio das Américas) com objetivos semelhantes, qual seja, o de criar uma área livre de barreiras ao comércio e ao investimento entre os países da região.

Parece que, no caso brasileiro, ocorre uma antecipação aos termos advogados pela OMC e pela ALCA, pois com o exposto no Anteprojeto, em relação à revalidação dos diplomas, à participação do capital estrangeiro e à abertura para a EAD - pelo menos, nos termos em que foi colocada -, importantes barreiras serão eliminadas e um caminho sem volta estará aberto para a transnacionalização da educação superior no país. Em síntese, a soberania nacional para o oferecimento da educação superior encontra-se em risco, processo que poderá culminar com a desnacionalização das ações educativas brasileiras e o coroamento da invasão cultural (estadunidense).

\section{Sistema de Educação Superior e Privatização}

Se tomarmos a análise da educação superior historicamente, verificase que a privatização do sistema brasileiro não é um fenômeno novo e que, mesmo considerando a permanente tensão entre interesses públicos e privados no âmbito do próprio Estado e das demais esferas da atividade humana, mesmo que se relevem as inúmeras lutas travadas em prol do pólo público, pode-se identificar uma crescente mercantilização do sistema de educação superior no país, pelo menos desde a Lei n. ${ }^{\circ} 5540$ de 1968 ou Lei da Reforma Universitária de 68.

É preciso esclarecer, ainda, que muito embora a privatização da educação esteja vinculada diretamente à diminuição do investimento estatal para a prestação de um determinado serviço, ela comporta outras facetas, podendo inclusive "conviver" com a manutenção ou até com o aumento do gasto público destinado ao setor em questão. Como se discutiu, anteriormente, em relação ao ProUni, a delegação de responsabilidades públicas para instituições privadas comerciais de educação superior também significa privatizar, assim como, a edição de medidas facilitadoras que incentivem o aumento da oferta privada e até, em instituições públicas, a introdução de dinâmicas mercadológicas também se qualifica para o rol das privatizações. 
Reforma da educação superior no Brasil: análises sobre a transnacionalização e privatização

Infelizmente, a esperança que se acalentou com a eleição do governo Lula, quanto à reversão dessa tendência histórica no país, mostrou-se vã e a análise do terceiro Anteprojeto de Lei da Reforma da Educação Superior não foge à regra.

Primeiramente, pode-se visualizar no Anteprojeto vitórias da "burguesia de serviços" brasileira, hoje responsável por 89,9\% do total das instituições de educação superior e por 70,8\% das matrículas (BOITO, 1999; BRASIL, INEP, 2003). Como resultado da pressão exercida, por meio do Fórum Nacional da Livre Iniciativa na Educação, do qual participam o Conselho de Reitores das Universidades Brasileiras (CRUB), a Associação Brasileira de Mantenedoras de Ensino Superior (ABMES), e mais de duas dezenas de entidades representativas dos empresários da educação; a isenção fiscal está mantida e ampliada (com o PROUNI); bem como o financiamento público indireto realizado pelo FIES (Fundo de Financiamento ao Estudante do Ensino Superior).

Mas as vitórias do setor privado comercial não pararam aí. A análise do terceiro Anteprojeto, em relação ao segundo (divulgado em 6 de dezembro de 2004), demonstra que houve uma diminuição dos mecanismos de regulação do ensino privado, de modo que o controle sobre as mantenedoras praticamente desapareceu. Além disso, flexibilizou-se a oferta de cursos, inclusive as condições para o credenciamento dos centros universitários, reduzindo de 12 para 8 cursos a exigência mínima para constituição dessas IES (Artigo 22, I).

No outro pólo, o das instituições públicas, o quadro também não é positivo, como demonstra a análise das mudanças sugeridas para o financiamento das instituições federais de ensino superior (IFES). Sobre essa questão, o Anteprojeto define basicamente os seguintes aspectos: (1) exclui dos repasses o montante referente aos gastos com aposentados e pensionistas; (2) elimina, ainda, parte dos gastos com a infra-estrutura da saúde (artigo 49, V e VI), e (3) define, no artigo 49, um patamar de financiamento nunca inferior a $75 \%$ dos 18\% da receita resultante de impostos, inclusive transferências, que a Constituição Federal vinculou em seu artigo 212 à manutenção e desenvolvimento do ensino. Mesmo considerando tudo isso, conforme estudiosos do tema, o cômputo geral não irá alterar significativamente o padrão de financiamento das IFES. Em síntese, o financiamento das IFES aumentará um pouco, mas não ficará muito distante dos $0,6 \%$ do PIB, que é aproximadamente 0 índice atual, e continuará distando em muito do índice histórico, que era de 0,95\%, em 1989.

Assim, os recursos definidos para as IFES, embora ligeiramente expandidos, são insuficientes para contemplar a expansão e interiorização da rede $^{4}$, a recuperação de remuneração da força de trabalho docente, bastante

4 Tanto o Plano Nacional de Educação (2000) quanto o Anteprojeto da Reforma prevêem a expansão do ensino público, propondo a meta de 40\% das vagas neste setor até 2011. 
deteriorada, bem como a assistência estudantil em moldes consistentes com políticas agressivas de inclusão social.

Todavia, o Anteprojeto fornece pistas para equacionar o problema: além da vergonhosa proposta de financiamento da educação por jogos de azar, como as Loterias Federais (Artigo 58) ${ }^{5}$, sugere a diversificação das fontes de financiamento da educação realizada por meio das "receitas próprias das IFES, geradas por suas atividades e serviços" (Artigo 20, III) e a elaboração de "um plano de trabalho das IFES com suas fundações de apoio" (Artigo 43, \& $2^{\circ}$ ). São meras insinuações, mas lastimáveis pelos efeitos de privatização que podem gerar no âmbito universitário, pois indicam para a universidade pública que sua crise financeira pode ser amenizada, mediante a geração de receitas próprias, nomeadamente por meio de parcerias com o capital, sobretudo 0 industrial.

A análise desse quadro, tomado como um todo, remete à possibilidade de um aprofundamento da privatização da educação superior no país. A despeito dos discursos em prol do pólo público, do convincente diagnóstico antineoliberal muitas vezes apresentado pelos representantes governamentais; na prática (ou no papel), as soluções propostas em diversas passagens do Anteprojeto governamental permitem que se conclua em sentido contrário. Pelos balizamentos colocados em curso, seja pelas facilidades apontadas para as instituições privadas, ou pela mera manutenção da situação de precariedade das instituições federais, é possível se antever um aprofundamento da privatização do sistema de educação superior no Brasil, a partir da aprovação do Anteprojeto proposto para a reforma desse nível de ensino.

\section{Alguns Efeitos da Privatização da Educação Superior Pública}

Infelizmente, o cenário acima apresentado não é exclusivo da realidade brasileira. Pode-se dizer que, guardadas as especificidades, trata-se de uma mudança global que apresenta como motivações centrais: (1) a deserção do Estado de seu necessário protagonismo na implementação da universidade como um bem público e direito de cidadania e do seu papel de mantenedor pleno dessa instituição social; (2) uma gestão da educação superior nos moldes das empresas e (3) a privatização ou semiprivatização das próprias universidades públicas. Um pressuposto relacionado a esse quadro, abordado por Schugurensky e Naidorf (2004), é que

5 Conforme Lima (2005) bem lembrou, isso não é novidade na política educacional brasileira. Por meio do Decreto n⿳0 62.937 de 1968, o então Ministro da Educação do governo militar, Tarso Dutra, instituiu a formação de um Grupo de Trabalho para a elaboração de um anteprojeto de lei da reforma universitária que já apontava nesse sentido. 
[...]o setor privado é sempre mais eficaz e eficiente do que o setor público, considerado como inerentemente desperdiçador, ineficiente e corrompido. Essas crenças levaram a demandas pormais universidades privadas e por mais empreendedorismo nas universidades públicas. Conseqüentemente, ainda segundo esse argumento, as universidades deveriam ser pressionadas para se tomarem mais empresariais e oferecerem seus serviços e produtos (pesquisa, consultoria, formação, etc.) a um imenso leque de consumidores (inclusive ao governo) numa busca por bens da maior qualidade pelo menor preço ( $\mathrm{p}$. 1002).

Enfim, ocorre uma mudança geral rumo a uma universidade mais empresarial que é inseparável da crença neoliberal na superioridade das dinâmicas do mercado em relação à dinâmica acadêmica, a qual é percebida como fundamentalmente centrada em si mesma.

Todavia, é preciso destacar que embora a descapitalização da universidade pública seja um fenômeno global, suas conseqüências são significativamente diferentes no centro, na periferia e na semiperiferia do sistema mundial (SANTOS, 2004). Na periferia e especialmente em determinadas áreas do conhecimento - como as humanas e sociais - , a busca de receitas alternativas no mercado ou fora dele é virtualmente impossível e a crise institucional pode atingir proporções catastróficas.

De todo modo, na periferia ou no centro, a aplicação desse receituário remete a dois efeitos principais, analisados a seguir, tal como se apresentam na realidade brasileira: (1) a neoprofissionalização do sistema ou reatualização do modelo napoleônico e (2) a idéia da ciência dirigida pela economia, a ênfase na produção de conhecimento economicamente útil, isto é, comercializável.

\section{(1) A Neoprofissionalização do Sistema de Educação Superior}

O mandamento que ainda rege o ensino superior brasileiro - a Lei $\mathrm{n} . \underline{\mathrm{o}}$ 5.540 de 1968 - foi definido sob a égide da ditadura militar e de toda uma legislação que tolhia a liberdade na sociedade e na academia. Do que aqui interessa, essa reforma, entre outras coisas, determinava o fim da cátedra vitalícia, tornava obrigatório o regime departamental, definia linhas gerais para a carreira docente e estabelecia a obrigatoriedade da associação ensino e pesquisa. Desse modo, mesmo os críticos não hesitam em relacioná-la ao modelo humboldtiano de universidade e de relevar sua contribuição para a institucionalização da pesquisa e da pós-graduação stricto sensu no país.

Todavia, a maior parte das instituições de educação superior não seguiu esses preceitos da Lei n. ${ }^{0} 5540$ e mantiveram uma tendência, ademais 
visível desde a época das escolas profissionais do Império, que prima pela organização administrativa voltada para a formação de profissionais, pelo ensino universitário que segue "um padrão canônico clássico, de transmissão informativa do conhecimento acumulado nas disciplinas, nem sempre atualizada e de reprodução dos saberes consagrados pelo 'paradigma normal' da ciência”, enfim, pela ausência de estruturas de pesquisa e pós-graduação consolidadas, delegando aos seus docentes uma dedicação quase exclusiva às atividades de ensino, muitas vezes, de qualidade duvidosa, de modo que somente em algumas grandes universidades, na sua maioria públicas, pode-se perceber a adesão a um modelo humboldtiano de educação superior (LUZ, 2005, p.10).

Este quadro tendeu a se aprofundar com o crescimento quantitativo do setor, especialmente a partir de meados dos anos 90, não só pelas facilidades criadas para a abertura e expansão das instituições privadas, particularmente as instituições privadas organizadas como empresas comerciais, nas quais inexistem condições para a produção de conhecimento, mas também por conta das restrições financeiras impostas pela retirada gradativa do Estado da manutenção e expansão do setor público federal, cujas instituições, muitas vezes, também se encontram acuadas e restritas às atividades de ensino.

Além disso, a formação profissional, no caso brasileiro, tem sido marcada pela edição de medidas legais baseadas num imediatismo pragmático, em ondas de expansão feita às pressas e sem garantias para a qualidade do ensino. A atual Reforma da Educação Superior não foge à regra. A compra de vagas na iniciativa privada, com o ProUni, a abertura de mais de três dezenas de novos campi e a criação de novas instituições universitárias sem a necessária contrapartida da área econômica configuram um quadro de expansão que enfoca unicamente o ensino e de baixa qualidade. Assim, longe de resolver ou de corrigir a distribuição desigual dos bens educacionais, o que seria alcançado pela expansão das vagas tende a aprofundar as condições históricas de discriminação e de negação do direito à educação superior de qualidade a que são submetidos os setores mais pobres da população.

O atual Anteprojeto de Lei da Reforma da Educação Superior, até certo ponto, cristaliza a distribuição desigual dos bens educacionais. Além das universidades, centros universitários e faculdades, o Anteprojeto apresenta as universidades especializadas (Artigo 18, § único); os centros universitários especializados (Artigo 22, \& único), os cursos seqüenciais (Artigo 6ํㅡ, V-a), os cursos a distância e os cursos para alunos não-regulares (Artigo 10). Gera 0 que se vem chamando "certificação em larga escala"; de diplomas, certificados e atestados, obviamente, com valores bastante distintos no mercado de trabalho e na bagagem de conhecimentos - especialmente os críticos - auferidos pelos estudantes. Ao flexibilizar as condições de prestação desse serviço, apro- 
Reforma da educação superior no Brasil: análises sobre a transnacionalização e privatização

funda a heterogeneidade do sistema e produz desigualdade educacional (LMA, 2005). Em síntese, a fragmentação do grau acadêmico de graduação amplia-se para que se alcance de forma rápida e pragmática a "universalização" desse nível de ensino, mas tudo isso se dá às expensas da universalização da qualidade.

\section{(2) A Mercadorização do Conhecimento Científico}

Como se expôs anteriormente, são poucas as instituições de educação superior no Brasil a apresentarem uma sólida infra-estrutura para, além do ensino, cumprirem a meta universitária de produção de conhecimento. A maior parte dessas instituições é pública, qual seja, deveria ser financiada pelo Estado, com autonomia para o desenvolvimento da pesquisa original e inovadora. Contudo, com a progressiva diminuição do investimento estatal, assiste-se a um quadro de reformulação política e econômica, que acirra 0 ajuste das políticas sociais, entre elas as educacionais, às reformulações econômico-financeiras em curso. De outro modo, assiste-se a uma acomodação das questões educacionais às regras da mercantilização, incluindo as atividades de pesquisa, de modo que mesmo as universidades produtoras de conhecimento vêem-se às voltas com a tarefa adicional de captarem recursos por sua própria conta.

Este é o dinamismo interno às instituições, que induz, em última instância, à mercadorização do conhecimento, a ponto de Sevcenko (2000) referir-se, com acertada ironia, às novas facetas do trabalho acadêmico:

O professorideal agora é um híbrido de cientista e corretorde valores. Grande parte do seu tempo deve ser dedicado a preencher relatórios, alimentar estatísticas, levantarverbas e promovervisibilidade para si e seu departamento. $O$ campus vai se reconfigurando num gigantesco pregão. $O$ gerenciamento de meio acabou se tomando fim na universidade. A idéia é que todos se empenhem, no limite de suas forças [...]. (SEVCENKO, 2000, p. 7)

Em determinadas áreas do conhecimento, todo esse clima é muito mais intenso e ocorre com muito mais freqüência porque o assédio à universidade pela produção de conhecimento relaciona-se diretamente à produção ou à capacidade das empresas, mediante a inovação tecnológica e pelo conhecimento técnico-científico que a torna possível, intensificarem a concorrência em proveito próprio. Pode-se afirmar que é justamente dessa possibilidade de lucro que advém o crescente reconhecimento mundial da importância da produção de conhecimento e a pressão para que a universidade 0 produza e o venda posteriormente. De todo modo, é preciso que se tenha claro que a demanda mercadológica pelo conhecimento não se refere a qual- 
quer produção tecnológica e científica, mas àquela que direta ou indiretamente possa incrementar a concorrência intercapitalista. Do mesmo modo, a consciência da importância estratégica das instituições de educação superior e da necessidade do seu incremento, advogada mundialmente, também não é neutra e desinteressada, mas apresenta profundas conexões com a competitividade econômica, com a possibilidade da produção de um conhecimento que dê apoio ao processo de acumulação; ou à garantia da ordem, ao controle social e à legitimação do próprio sistema.

Assim, o recente interesse pela educação superior comporta, ao mesmo tempo e organicamente, ameaças a muitos valores que são caros às universidades. Especialmente a sua autonomia é sacrificada pela subordinação a uma ordem imposta externamente, que se sobrepõe à agenda institucional, que limita a autodeterminação e a liberdade acadêmica, de modo que, muitas universidades, nas últimas décadas, já vêm perdendo terreno na fixação de seus objetivos e propósitos e estão sendo constrangidas a adequar grande parte de suas atividades às demandas do mercado, à agenda estatal e/ou à internacional (SGUISSARDI, 2002). Com a mercadorização do conhecimento, a "lealdade acadêmica" fica ameaçada por grupos poderosos, "tanto dentro quanto fora da academia, que exigem lealdade, antes de tudo, para com a instituição - isto é, para com a empresa que paga a fatura" (MEEK, 2004, p.1039).

Nos chamados países da periferia, esse quadro torna-se mais agudo, pois a dinâmica mundial a exigir mais inovação e conhecimento apropriável pela cultura empresarial encontra uma instituição sedenta de recursos, atores frágeis para a negociação e ávidos para ultrapassar a crise financeira, mediante a geração de receitas próprias, nomeadamente através de parcerias com o capital, sobretudo o industrial, sem maiores escrúpulos.

No Brasil, já ocorrem inegáveis traços nas políticas de pesquisa que demonstram esse raciocínio. O próprio Anteprojeto da Reforma da Educação Superior recomenda que a CAPES defina as áreas do conhecimento a serem incentivadas, "especialmente aquelas que atendam às demandas de política industrial e comércio exterior" (Artigo 12, IV), ou seja, recomenda a mais eficaz aplicação dos recursos em pesquisas que possam trazer retorno para o fortalecimento do capital nacional industrial e agropecuário (exportador).

Todavia, mesmo considerando o clima mundial e nacional a requerer produção científica e tecnológica das instituições de ensino superior, é preciso advertir aos entusiastas da captação de recursos na iniciativa privada, que estudiosos do assunto chamam atenção para as especificidades do caso brasileiro: 
De fato, um importante contraste entre a tendência dos países mais avançados e o caso brasileiro refere-se, por exemplo, ao [pequeno] engajamento do setor empresarial nos esforços inovativos e de P\&D. [...] Assim, apesar de importantes esforços, o ajuste produtivo realizado pela maioria das empresas brasileiras tem consistido basicamente de uma estratégia defensiva de racionalização da produção, visando reduzir custos. Tal movimento tem se dado basicamente através da introdução parcial e localizada de equipamentos de automação industrial, e de novas técnicas organizacionais do processo de trabalho, ou através do 'enxugamento' da produção, com redução de pessoal e eliminação de linhas de produção (movimentos de desverticalização, subcontratação e especialização). (CASSIO LATO, LASTRES, 2000, p. 244-245)

Mesmo considerando a singularidade da cultura empresarial brasileira, a mercadorização do conhecimento tem levado a novos tipos de relações na academia baseadas numa concepção gerencial que assimila os princípios, parâmetros e as feições das organizações econômicas e a análise do cotidiano das instituições escolares põe a nu alguns vieses bastante graves: 0 individualismo no enfrentamento das situações problemáticas acadêmicas; o acirramento da competitividade nas instituições educacionais; a supervalorização das avaliações em escala nacional, de cunho pseudo-meritocrático, para não dizer meramente classificatório, normativo e punitivo; o imediatismo em relação às demandas do mercado de trabalho; a centralidade da categoria "produtividade" (do agente pesquisador, ou do programa institucional de pesquisa em que este se insere), tomada de empréstimo do mundo dos negócios; em síntese, uma construção ideológica, no próprio tecido escolar, nada desprezível, porque miúda, caucionada pelo discurso do mérito, mas pretensiosa nas intenções, na medida em que procura agir desmontando os direitos sociais que pudessem ser ordenados como compromisso social coletivo.

\section{Considerações Finais}

Concluindo, pode-se afirmar que o Anteprojeto de Lei da Reforma da Educação Superior, se aprovado, somado às medidas legais que o precederam, poderá trazer sérias conseqüências para a política de ciência, tecnologia e inovação tecnológica e para a esfera educacional de nível superior. Além disso, a análise aqui desenvolvida remete à dura conclusão de que nesse campo - o da educação superior -, como no macroeconômico, nenhuma grande ruptura pôde ser visualizada em relação às políticas anteriores. Ao contrário, o que se constata é a continuidade das teses postuladas e praticadas pelo governo Fernando Henrique Cardoso e pelos organismos financeiros multilaterais, pois, dentre outros aspectos, a reforma em curso não escapa de 
uma concepção privatista da educação superior, seja por certas garantias dadas às IES privadas ou ainda pela privatização interna das universidades públicas.

Quanto ao seu encaminhamento futuro, visualiza-se a submissão à ortodoxa equipe do Ministro da Fazenda Antonio Palocci Filho como inevitável, de onde poderão advir maiores restrições ao Anteprojeto, especialmente as relacionadas ao financiamento. Uma vez no Congresso Nacional, novos problemas poderão ocorrer, podendo ser aprovado um texto mais perversamente voltado à privatização do sistema como um todo, pois o poderoso lobby privatista tentará ampliar suas conquistas, como a admissão de um maior percentual de participação de capital estrangeiro nas IES privadas e maiores facilidades para difusão do comércio transfronteiriço por meio de educação a distância.

Mesmo que esse Anteprojeto não seja aprovado pelo Congresso Nacional, os problemas permanecerão, pois questões centrais já foram resolvidas com o SINAES, o ProUni, a Lei de Inovação Tecnológica e a das Parcerias Público-Privadas. Com esse espectro legal aprovado, já se pode prever a consolidação de profundas transformações no sistema de educação superior que se encaminham num sentido oposto pelo qual se tem lutado.

Assim, a análise do Anteprojeto e da legislação que o precedeu não permite antever, com otimismo, a aprovação de uma Lei de Educação Superior que fortaleça o setor público e promova uma efetiva regulação do setor privado comercial; que garanta a autonomia da universidade em relação aos interesses do Estado e do mercado, que fortaleça práticas que remetam ao pólo público e que, portanto, combatam a mercantilização do sistema de educação superior.

De todo modo, mesmo considerando a conjuntura adversa, há que se registrar a existência, no Brasil, de movimentos que se contrapõem, seja no campo acadêmico ${ }^{6}$, ou no campo sindical ${ }^{7}$, às políticas para a educação superior aqui criticadas. Tais iniciativas críticas e insurgentes dão consistência à crença de que, em se tratando de universidade, sempre existe a possibilidade de um momento de suspensão, onde se reelabora outro código de sociabilidade, outro código de civilidade e de relação com o público. A universidade brasileira já o fez em outros momentos!

6 Sobre a crítica acadêmica, é de valia a consulta aos trabalhos apresentados na 28a Reunião Anual da Associação Nacional de Pós-Graduação e Pesquisa em Educação (ANPEd), especialmente os do Grupo de Trabalho 11, que versam sobre Políticas da Educação Superior (http:// www2.uerj.br/ anped11).

7 No momento da escrita desse texto, mais de trinta universidades públicas brasileiras estavam em greve, por melhorias salariais e de condições de trabalho, bem demonstrando que há existência de amplos setores insatisfeitos com os rumos das políticas para a educação superior brasileira. 


\section{Referências}

BOITO JR, A. Política neoliberal e sindicalismo no Brasil. São Paulo: Xamã, 1999.

BRASIL. Lei noo 11.096, de 13 de janeiro de 2005. Institui o Programa Universidade para Todos - PROUNI. Disponível em: <http:// www.presidencia.gov.br>. Acesso em: 1 dez. 2005.

BRASIL. Lei n.o 11.079, de 30 de dezembro de 2004. Institui normas gerais para licitação e contratação de Parceria Público-Privada (PPP) no âmbito da administração pública. Disponível em: $\lfloor\underline{h} t t p: / /$ www.presidencia.gov.br $>$. Acesso em: 1 dez. 2005.

BRASIL. Lei n.o 10.973, de 02 de dezembro de 2004. Dispõe so bre incentivos à inovação e à pesquisa científica e tecnológica no ambiente produtivo e dá outras providências. Disponível em: 〈http:// www.presidencia.gov.br $>$. Acesso em 1 dez. 2005.

BRASIL. Decreto n. 5224, de 1 de outubro de 2004. Dispõe sobre a organização dos Centros Federais de Educação Tecnológica e dá outras providências. Disponível em: <http://www.presidencia.gov.br>. Acesso em: 1 dez. 2005.

BRASIL. Decreto n.o 5205, de 14 de setembro de 2004. Regulamenta a Lei $\mathrm{n}^{2}$ 8.958, de 20 de dezembro de 1994, que dispõe sobre as relações entre as instituições federais de ensino superior e de pesquisa científica e tecnológica e as fundações de apoio. Disponível em: <http://www.presidencia.gov.br >. Acesso em: 1 dez. 2005.

BRASIL. Decreto n.o 5154, de 23 de julho de 2004. Regulamenta $0 \backslash 1$ "art36\%C2\%A72" $§ 2^{\circ}$ do art. 36 e os $\backslash 1$ "art39" arts. 39 a 41 da Lei $n^{0} 9.394$, de 20 de dezembro de 1996, que estabelece as diretrizes e bases da educação nacional, e dá outras providências. Disponível em: <http:// www.presidencia.gov.br>. Acesso em: 1 dez. 2005.

BRASIL. Lei n.o 10861, de 15 de abril de 2004. Institui o Sistema Nacional de Avaliação da Educação Superior - SINAES e dá outras providências. Disponível em: <http://www.presidencia.gov.br>. Acesso em: 15 maio 2004.

BRASIL. Plano Nacional de Educação, de 2000. Disponível em: <http:// portal.mec.gov.br/arquivos/pdf/pne.pdf>. Acesso em: 10 out. 2005.

BRASIL. Lei no 5540, de 28 de novembro de 1968. Fixa normas de organização e funcionamento do ensino superior, sua articulação com a escola 
média e dá outras providências. Disponível em: <http://www.presidencia.gov.br>. Acesso em: 1 dez. 2005.

BRASIL, INEP. Censo da Educação Superior 2003. Disponível em: <http:// www.inep.gov.br>. Acesso em: 10 out. 2005.

BRASIL, MEC. Anteprojeto de Lei da Reforma da Educação Superior, de 29 de julho de 2005. Estabelece normas gerais para a educação superior no país, regula a educação superior no sistema federal de ensino. Disponível em: <http://www2.uerj.br/ anped11>. Acesso em: 1 dez. 2005.

CAFARDO, S. I. Procura diminui e particulares têm de enfrentar mudanças. Portal Universia. Disponível em: <http:// www.editau.com.br>. Acesso em: 17 out. 2005.

CARVALHO, C. H. A. Política de ensino superior e renúncia fiscal: da reforma universitária de 1968 ao PROUNI. In: REUNIÃO ANUAL DA ANPED, 28., Caxambu, 2005. Anais... Caxambu, 2005. Disponível em: <http:/ / www2.uerj.br/ anped11>. Acesso em: $1 \mathrm{dez} .2005$.

CASSIOLATO, J. E.; LASTRES, H. M. M. Sistemas de inovação: políticas e perspectivas. Parcerias Estratégicas, n. 8, p. 237-256, maio, 2000.

HOPER EDUCACIONAL; CM CONSULTORIA; IDEAL INVEST. Análise Setorial do Ensino Superior Privado no Brasil; tendências e perspectivas 20052010. Disponível em: <http://www.abmes.org.br/Seminarios/ SEMINARIOS.htm>. Acesso em: 5 dez. 2005.

JURUÁ, C. V. PPP: os contratos de parceria público-privada. Disponível em: <http://www.lpp-uerj.net/outrobrasil/documento>. Acesso em: 3 ago. 2004.

LMA, K. R. de S. Capitalismo dependente e "Reforma Universitária Consentida": a contribuição de Florestan Fernandes para a superação dos dilemas educacionais brasileiros. In REUNIÃO ANUALDA ANPED, 28., Caxambu, 2005. Anais... Caxambu, 2005. Disponível em: 〈http://www2.uerj.br/ anped11>. Acesso em: 1 dez. 2005.

LUZ, M. T. Prometeu acorrentado: análise sociológica da categoria produtividade e as condições atuais da vida acadêmica. PHYSIS: Revista de Saúde Coletiva, Rio de Janeiro, v. 15, n.1, p.39- 57, 2005.

MANCEBO, D. Reforma universitária: reflexões sobre a privatização e a mercantilização do conhecimento. Educação \& Sociedade, Campinas, v. 25, n. 88, p. 845-867, 2004-a. 
MANCEBO, D. Universidade para todos: a privatização em questão. Proposições, Campinas, v. 15, n. 3, p. 75-90, 2004-b.

MEEK, V. L Produção do conhecimento na educação superior australiana: do acadêmico ao comercial. Educação \& Sociedade, v.25, n. 88, p. 1023-1043, 2004.

MÉSZAROS, I. A educação para além do capital. São Paulo,: Bomtempo, 2005.

ROTHEN, J. C.; SCHULZ, A. Sinaes: do documento original à legislação. In REUNIÃO ANUAL DA ANPED, 28., Caxambu, 2005. Anais... Caxambu, 2005. Disponível em: <http://www2.uerj.br/ anped11>. Acesso em: 1 dez. 2005.

SANTOS, B. de S. Universidade no século XXI: para uma reforma democrática e emancipatória da universidade. São Paulo: Cortez, 2004.

SEVCENKO, N. O professor como corretor. Folha de São Paulo, São Paulo, 4 jun. 2000. Caderno Mais, 6-7.

SCHUGURENSKY, D.; NAIDORF, J. Parceria universidade-empresa e mudanças na cultura acadêmica: análise comparativa dos casos da Argentina e do Canadá. Educação \& Sociedade, v.25, n. 88, p. 997-1022, out. 2004.

SGUISSARDI, V. Educação superior no limiar do novo século: traços internacionais e marcas domésticas. Revista Diálogo Educacional, Curitiba, v. 3, n. 7, p. 121-144, set./dez. 2002.

Recebido: 06 de dezembro de 2006 Aprovado: 12 de fevereiro de 2007 